\title{
Plasma membrane intrinsic proteins PIP1;1 and PIP1;3 contribute to the tolerance to nitrogen deficiency in potato
}

\author{
Anna Maria Jozefowicz ${ }^{1}$, Manuela Desiree Bienert ${ }^{1}$, Adriana Garibay ${ }^{1}$, Ricardo Giehl ${ }^{2}$, \\ Andrea Matros ${ }^{3}$, Annegret Schum ${ }^{4}$, Gerd Patrick Bienert ${ }^{1}$, and Hans-Peter Mock ${ }^{1}$ \\ ${ }^{1}$ IPK Gatersleben \\ ${ }^{2}$ Affiliation not available \\ ${ }^{3}$ Leibniz Institute of Plant Genetics and Crop Plant Research \\ ${ }^{4}$ Julius Kühn-Institut Bundesforschungsinstitut für Kulturpflanzen
}

June 3, 2020

\begin{abstract}
Nitrogen (N) deficiency is one of the major constraints for potato (Solanum tuberosum L.) production, due to its shallow root system and poor capabilities of $\mathrm{N}$ mobilization from the deeper layers of the soil. The aim of this study was to elucidate plasma membrane (PM) proteins potentially involved in the tolerance towards $\mathrm{N}$ deficiency. We compared the PM proteome of the two potato cultivars 'Lambada' and 'Topas', contrasting in their $\mathrm{N}$ deficiency response under in vitro conditions. Using mass spectrometry we identified 65 proteins, which were differentially abundant in the two cultivars when submitted to $\mathrm{N}$ deficiency. Amongst those, candidate proteins were selected based on their potential to be involved in $\mathrm{N}$ transport under deficient conditions. Two members of the aquaporin family, StPIP1;1 and StPIP1;3, were studied in more detail. By means of a yeast growth assay we showed that these proteins do not facilitate transport of ammonia. The Arabidopsis (Arabidopsis thaliana) knockout mutants AtPIP1;1 and AtPIP1;3 showed a reduced N content and accumulation of anthocyanins under $\mathrm{N}$ deficiency. We conclude that PIP1;1 and PIP1;3 are indirectly involved in the $\mathrm{N}$ uptake under $\mathrm{N}$ deficient conditions and contribute to an increased $\mathrm{N}$ deficiency tolerance.
\end{abstract}

\section{Summary statement}

Root plasma membrane proteome profiling of two potato cultivars reveals the participation of the two members of the aquaporin family PIP1;1 and PIP1;3 in the cultivar specific response to nitrogen deficiency.

\section{Introduction}

The productivity of most field crops is sensitive to the availability of $\mathrm{N}$ in the soil. Globally, around 85-90 metric tons of nitrogenous fertilizer is added to arable soils each year, an amount predicted to be more than doubled by 2050 (Tilman, 1999). The production of nitrogenous fertilizer is energy and cost demanding in modern crop production systems. Due to the effects of nitrate leaching, denitrification and ammonia volatilization, which have been proved environmentally damaging (Masclaux-Daubresse et al., 2010; Shaviv \& Mikkelsen, 1993), it has been estimated that only 30-50\% of fertilizer-supplied $\mathrm{N}$ is taken up by crop plants, a range which reflects the combined influence of soil type, environment and plant species (Good, Shrawat, \& Muench, 2004). Potato is an important source of food and industrial starch. N utilization efficiency is especially poor in potato, on account of its shallow root system (Iwama, 2008) exacerbated by the fact that the crop is frequently grown on highly leachable sandy soils (Cambouris, Zebarth, Nolin, \& Laverdiere, 2008). The aim to improve $\mathrm{N}$ use efficiency has become important in crop plant breeding research (Chao \& Lin, 2015; Garnett, Plett, Heuer, \& Okamoto, 2015; Guo, Wang, Fan, Chen, \& Cui, 2016). In this respect, 
progress has been made in sugarcane, maize and rice (Hajari, Snyman, \& Watt, 2015; Ju et al., 2015; P. C. Li et al., 2015), but not in potato.

In plants, the interaction with various biotic and abiotic stress agents induces alterations in the protein composition of the PM (Komatsu, 2008). A better understanding of the PM proteome response to various environmental stimuli - and in particular to $\mathrm{N}$ deficiency - is seen as providing a route to the development of stress tolerant plants (Cordwell \& Thingholm, 2010; Komatsu et al., 2009). The PM acts both, as a selective barrier between the cell and the external environment and as a sensor for the prevailing environmental conditions (Barkla \& Pantoja, 2010). It controls a multiplicity of cellular processes such as transport of metabolites and ions, cell differentiation and proliferation, endocytosis, and supports energy generation and signal transduction (Komatsu, 2008; Ray, Kassan, Busija, Rangamani, \& Patel, 2016). The transport across membranes, required for acquisition and release of nutrients and signaling molecules, is achieved primarily through integral membrane proteins (Frommer et al., 1994). Members of four transporter families participate in root nitrate uptake, distribution and storage, including proteins from the nitrate transporter 1/peptide transporter family (Leran et al., 2014), the nitrate transporter 2 family (NRT2) (Orsel, Krapp, \& DanielVedele, 2002), the chloride channel family (Barbier-Brygoo et al., 2011), and slow anion associated channel homologs (Negi et al., 2008). Ammonium uptake is facilitated by members of the ammonium transporter (AMT) family (Loque \& von Wiren, 2004).

Since the PM constitutes a complex platform allowing the translation of external signals into finely tuned appropriate acclimation responses, the ability of plants to exploit several sources of $\mathrm{N}$ displays an intricate network in which signaling and regulatory proteins play a key role (Gronnier, Gerbeau-Pissot, Germain, Mongrand, \& Simon-Plas, 2018). Getting insights into this complex network through proteomic approaches is hampered, because the PM proteins are underrepresented when proteome analysis is performed. Thus, membrane-specific approaches are necessary to study the roles played by PM proteins. However, the number of studies on root PM proteomes remain scarce (Cheng et al., 2009; Hashimoto, Toorchi, Matsushita, Iwasaki, \& Komatsu, 2009; Voothuluru, Anderson, Sharp, \& Peck, 2016; Witzel et al., 2018) and are lacking for potato. To unveil key contributors involved in the low $\mathrm{N}$ tolerance, we made use of the contrasting response to $\mathrm{N}$ deficiency of the two potato cultivars 'Lambada' (sensitive) and 'Topas' (tolerant). Both cultivars were already characterized and described to differ at the physiological (Schum \& Jansen, 2012, 2013, 2014; Schum, Meise, Jansen, Seddig, \& Ordon, 2017) and at the whole proteome (Jozefowicz, Hartmann, Matros, Schum, \& Mock, 2017; Meise et al., 2017) level. Here, we report on the effect of N deficiency on the root PM proteome composition of the two potato contrasting cultivars and present candidate proteins likely playing a role in the acclimation of the tolerant cultivar to $\mathrm{N}$ deficiency.

\section{Materials and Methods}

Plant material - potato

Plant cultivation and stress treatments of two genotypes contrasting in their $\mathrm{N}$ deficiency response, namely 'Lambada' (sensitive) and 'Topas' (tolerant), were performed exactly as described (Jozefowicz et al., 2017). At the time of root appearance, after one week of cultivation, the nutrient solution was exchanged. Control plants were moved to fresh medium containing the original $20.6 \mathrm{mM} \mathrm{NH}_{4} \mathrm{NO}_{3}$ and $18.8 \mathrm{mM} \mathrm{KNO}_{3}$ ) and the plants for deficiency treatment were transferred to a medium with $1 / 16$ of the $\mathrm{N}$ level. The loss of $\mathrm{K}$ (as a result of withholding $\mathrm{KNO}_{3}$ ) was compensated by the addition of $\mathrm{KCl}$. After seven days, roots were harvested, snap-frozen in liquid $\mathrm{N}_{2}$ and stored at $-80{ }^{\circ} \mathrm{C}$. The experiment was performed in triplicate with six vessels per condition and cultivar.

Plant material - Arabidopsis thaliana

Experiments on Arabidopsis were performed using the wild type (WT) ecotype Col-0 and the two T-DNA insertion lines GABI_437B11 (Atpip1;1 ) (Rosso et al., 2003) and SALK_051107 (Atpip1;3 ) (Alonso et al., 2003) obtained from the Nottingham Arabidopsis Stock Centre (Nottingham, United Kingdom). Homozygous mutants were selected by PCR with specific primers listed in Supplementary Table S1. Homozygous lines were selected based on the absence of a wild type amplicon and the presence of the T-DNA insertion 
(Supplementary Fig. S1). For the cultivation of plants on soil, 'Fruhstorfer Nullerde' (white-peat volcanic clay mixture) was used. The soil substrate was prepared as described previously (Pommerrenig et al., 2018) with some modifications. The $\mathrm{pH}$ of a white-peat volcanic clay mixture was first adjusted to around $\mathrm{pH} 5.5$ with $\mathrm{CaO}\left(3 \mathrm{~g} \mathrm{~kg}^{-1}\right)$ and $\mathrm{CaCO}_{3}\left(2 \mathrm{~g} \mathrm{~kg}^{-1}\right)$. After 1 week, the substrate was fertilized with $250 \mathrm{ml} \mathrm{kg}^{-1}$ of a modified Hoagland solution containing: $60 \mathrm{mM} \mathrm{NH}_{4} \mathrm{NO}_{3}, 23.5 \mathrm{mM} \mathrm{KH}_{2} \mathrm{PO}_{4}, 2.8 \mathrm{mM} \mathrm{K}_{2} \mathrm{SO}_{4}, 13.3 \mathrm{mM}$ $\mathrm{MgSO}_{4}, 420 \mu \mathrm{M} \mathrm{CuSO}_{4}, 360 \mu \mathrm{MnSO}_{4}, 2.5 \mathrm{mM} \mathrm{MnCl}_{2}, 3.3 \mu \mathrm{M} \mathrm{NaMoO}, 152 \mu \mathrm{M} \mathrm{NaFeEDTA}$ and $226 \mu \mathrm{M}$ $\mathrm{H}_{3} \mathrm{BO}_{3}$. $\mathrm{N}$ deficiency was achieved by reducing the $\mathrm{NH}_{4} \mathrm{NO}_{3}$ concentration to $30 \mathrm{mM} \mathrm{NH} \mathrm{NH}_{3}$. Leaves $(8$ plant replicates per condition, three independent repetitions of the experiment) were harvested after 5 weeks of growth, snap-frozen in liquid $\mathrm{N}_{2}$ and stored at $-80{ }^{\circ} \mathrm{C}$. The $\mathrm{N}$ and $\mathrm{C}$ contents of the leaves were measured using a Euro EA elemental analyser (HEKAtech, Wegberg, Germany). Statistical analysis was performed using SigmaPlot v13 (Systat Software, Erkrath, Germany) utilizing a two way analysis of variance (ANOVA) and the Holm-Sidak post hoc test. Additionally for the qRT-PCR analysis plants were grown using in vitro based conditions as described previously (Schlesier, Breton, \& Mock, 2003). To impose N deficiency, the medium's $\mathrm{N}$ content was reduced to $2 \mathrm{mM}$.

Enrichment of plasma membrane

For the PM enrichment of potato roots, all six vessels obtained from each independent biological experiment were pooled. The two phase PM enrichment protocol described by Hynek, Svensson, Jensen, Barkholt, and Finnie (2006) was modified to treat potato roots as described recently (Jozefowicz, Matros, Witzel, \& Mock, 2018). Briefly, the microsomal fraction of potato roots was obtained by differential centrifugation (15 min 10,000x $g, 50 \mathrm{~min} 50,000 \times \mathrm{g}, 4{ }^{\circ} \mathrm{C}$ ). Subsequently, $3 \mathrm{~g}$ of membrane suspension were loaded onto $9 \mathrm{~g}$ twophase mixture composed of $6.2 \%$ Dextran T500, 6.2\% PEG 3350, $8 \mathrm{mM} \mathrm{KCl} \mathrm{pH} \mathrm{7.8,} 300 \mathrm{mM}$ sucrose, $5 \mathrm{mM}$ potassium phosphate buffer. Loosely bound and soluble proteins trapped in vesicles were removed by washing the PM enriched upper phase pellet in Brij- 58 buffer (0.33 M sucrose, $0.2 \mathrm{M} \mathrm{KCl}, 5 \mathrm{mM}$ phosphate buffer ( $\mathrm{pH}$ 7.8), 0.2\% (w/v) Brij-58) (Alexandersson, Saalbach, Larsson, \& Kjellbom, 2004). Protein quantification was performed according to Bradford (1976). Proteins ( $5 \mu \mathrm{g}$ per fraction) were separated by electrophoresis through $11.25 \%$ sodium dodecyl sulphate polyacrylamide gels (Laemmli, 1970) and subsequent Western blot analyses performed as described elsewhere (Amme et al., 2005). The following antisera were used: anti-H ${ }^{+}$-ATPase (diluted 1:3000), anti-V-ATPase (1:3000), anti-VDAC (voltage dependent anion channel, 1:2000), anti-BiP (luminal binding protein, 1:8000) (Agrisera, Vannas, Sweden) and self-raised anti-MDAR (monodehydroascorbate reductase, 1:1000). The universal secondary antibody used was the goat polyclonal anti-rabbit conjugated with IRDye $800 \mathrm{CW}$ (1:15000), which enabled infrared fluorescence detection via a LI-COR Biosciences scanner (Bad Homburg, Germany). Relative quantification of the fluorescence signal was performed using Odyssey 3.0 software and mean values were compared using the Student's $t$-test.

\section{Protein extraction and digestion}

Protein extraction and tryptic digestion of the PM enriched upper phase were performed according to the protocol described previously (Jozefowicz et al., 2018). Prior to the processing by LC-MS, the resulting peptide mixtures were resuspended in $1 \%(\mathrm{v} / \mathrm{v})$ acetonitrile with $0.1 \%(\mathrm{v} / \mathrm{v})$ formic acid.

\section{Label-free quantification of proteins and data analysis}

The LC-MS analysis of peptides was performed using a Q-TOF Premier MS device coupled to a NanoAcquity system device (Waters Corporation, Eschborn, Germany) as described elsewhere (Jozefowicz et al., 2017). Two technical repetitions were run for the three independent experiments. Protein identification was performed using the ProteinLynx Global SERVER v2.5.3 software (Waters Corp.). The following parameters were used: automatic mass tolerance and fragment mass tolerance, one missed cleavage and variable modification: oxidation (Met), carbamidomethyl (Cys). MS data were searched against a potato database, based on the sequences from Solanum tuberosum group Phureja DM1-3 (PGSC_DM_v3.4_pep_representative, 39,031 entries) (X. Xu et al., 2011) annotated by means of the Blast2GO software (09.2014) (Conesa \& Gotz, 2008) and supplemented with sequences of human keratin and trypsin. Additional annotation using the UniProt database (http://www.uniprot.org/) was performed for the proteins of inter- 
est. Protein quantification was carried out using Progenesis QI for proteomics software (Nonlinear Dynamics, Newcastle, UK). Only proteins with more than one unique peptide were included in the analysis and those with ANOVA p-values $<0.05$ and a fold change $>1.5$ were considered as showing a significant degree of variation. Transmembrane regions were predicted by reference to the TMHMM Server v.2.0 (http://www.cbs.dtu.dk/services/TMHMM/) (Krogh, Larsson, von Heijne, \& Sonnhammer, 2001). Principal component analysis (PCA), Z-score normalization and hierarchical clustering based on the Euclidean distance method were carried out using the Perseus Framework (Tyanova et al., 2016). A full listing of the differentially expressed proteins has been placed, together with the raw data, in the IPK Gatersleben system e!DAL (Arend et al., 2014), available at: https://doi.ipk-gatersleben.de/DOI/15c49da1-7f23-4c8f9227-5695c1218b6a/2a5bce80-0e3b-484f-8878-0a4f3afe62b9/2/1847940088.

\section{Quantitative real time ( $R T)-P C R$}

The RNA extraction as well as qRT-PCR was performed as described previously (Jozefowicz et al., 2017) The reference sequences for potato were L2 and Aprt (primers as suggested by Nicot, Hausman, Hoffmann, and Evers (2005), while the primers targeting aquaporin genes were taken fromVenkatesh, Yu, and Park (2013). The primers for the A. thaliana aquaporin genes were those described by Alexandersson et al. (2010) and the reference genes were tip 41 and expr(Czechowski, Stitt, Altmann, Udvardi, \& Scheible, 2005).

\section{Extraction and UPLC-PDA profiling of phenylpropanoids}

Phenylpropanoid extraction and detection was performed as described (D. R. Xu et al., 2019). PDA-detection of phenylpropanoids was performed in a range between 210 and $800 \mathrm{~nm}$, at a resolution of $1.2 \mathrm{~nm}$ and a sampling rate of 20 points $\mathrm{s}^{-1}$. Spectra for phenylpropanoids and anthocyanins were recorded at 280 and 520 $\mathrm{nm}$, respectively. Total phenylpropanoid and anthocyanin contents were quantified as the total peak area of the compounds detected at 280 and $520 \mathrm{~nm}$, respectively, eluting between 2 and $7 \mathrm{~min}$. Data analysis was performed using the software packages Compass Data Analysis V4.4 and QuantAnalysis V4.4 (Bruker Daltonik GmbH, Bremen, Germany). Statistical analysis was performed using SigmaPlot v13 with a two way ANOVA and Holm-Sidak post-hoc test.

\section{Yeast strains and growth assay}

StPIP1;1 and StPIP1;3 were cloned from 'Topas' root cDNA using primers listed in Supplementary Table S2. PCR products were cloned in the USER-yeast expression vector pYeDP60u (Hamann \& Moller, 2007) and pRS426-pTPIu using an uracil excision-based improved high-throughput USER cloning technique (Nour-Eldin, Hansen, Norholm, Jensen, \& Halkier, 2006). A S. cerevisiae deletion mutant strain ( $\Delta$ mep1-3(-ura/-leu) (Anna Maria Marini's lab collection)) was co-transformed with either the two empty vectors (EV) pRS426-pTPIu and pYeDP60u (negative control transformant), or $h A Q P 8$ (in pYeDP60u) and an EV (pRS425-pTPIu) (positive control transformant). The two PIP isoforms, StPIP1;1 or StPIP1;3 in pYeDP60u, were co-transformed with maize ZmPIP2;5 in pRS425-pTPIu to localize the individual PIPs to the PM for transport assays. Co-transformation of StPIP1;1 orStPIP1;3 in pRS426-pTPI:N-terminal-green fluorescent protein (GFP) with ZmPIP2;5 in pRS425-pTPIu was performed for transport assays and for confocal microscopy (G. P. Bienert, Heinen, Berny, \& Chaumont, 2014). Transformed yeast was selected on synthetic medium containing $2 \%$ glucose, $50 \mathrm{mM}$ succinic acid/Tris base, $\mathrm{pH} 6.5,0.7 \%$ yeast nitrogen base without amino acids (Difco) and $0.2 \%$ proline. For the ammonium transport assay, yeast cells were diluted to different $\mathrm{OD}_{600}$ values $(1,0.01$, and 0.0001$)$ and spotted on synthetic medium containing $2 \%$ galactose, $50 \mathrm{mM}$ succinic acid/Tris base, $\mathrm{pH} 6.5,0.7 \%$ yeast nitrogen base without amino acids (Difco) and different concentrations of ammonium (2, 4, 5, 10, $20 \mathrm{mM}$ ammonium, supplied as ammonium sulfate) or $0.2 \%$ proline as positive control. Growth was documented after 8-10 days at $30{ }^{\circ} \mathrm{C}$.

\section{Microscopy}

Yeast cells expressing StPIP1;1 or StPIP1;3 GFP fusion proteins together with either the EV or ZmPIP2;5 were grown in liquid YPG medium. At an optical density at $600 \mathrm{~nm}$ of approx. 1, the fluorescence signal was observed. The localization was detected with a Zeiss LSM 780 confocal laser scanning microscope (Carl 
Zeiss, Jena, Germany) using a $488 \mathrm{~nm}$ laser line for excitation. GFP signals were detected at 491-536 nm.

\section{Results}

The effect of $N$ deficiency on the growth of potato in vitro

The potato cultivars 'Lambada' (sensitive) and 'Topas' (tolerant) were differentiated from a set of potato cultivars according to their Membership Function Value of stress tolerance calculated from previously published data (Jozefowicz et al., 2017; Schum et al., 2017). Here, the root PM proteome was analyzed after seven days of $\mathrm{N}$ deficiency. Under these conditions, the sensitive cultivar displayed a decrease in root fresh weight, whereas the growth of the tolerant cultivar remained unaffected. $\mathrm{N}$ deficiency at this time point did not lead to differences in the root $\mathrm{N}$ content or in the shoot fresh weights (Supplementary Fig. S2). This allowed us to analyze mechanisms leading to the early plant acclimation towards low N, excluding the secondary effects of long-term $\mathrm{N}$ deficiency, such as senescence. However, when the culture duration was prolonged, the differences between cultivars development and root architecture were more pronounced (Schum \& Jansen, 2012, 2013, 2014).

\section{Enrichment of PM from potato roots}

PM enrichment was critical for the subsequent membrane proteome analysis. The effectiveness of the twophase partitioning PM enrichment method was evaluated immunologically using compartment-specific antibody markers (Fig. 1). The abundance of the PM marker $\mathrm{H}^{+}$-ATPase was 13.3 -fold higher in the PM fraction compared to the original crude extract (CE), and three-fold higher than in the microsomal (M) fraction (Supplementary Fig. S3). In contrast, both the cytosolic marker MDAR (highly abundant in the soluble phase (S)) and the mitochondrial marker VDAC (highly abundant in the microsomal and the lower phase Dextran T500 phase (M and LP)), were barely detectable in the upper PM-enriched phase (PMe). $\mathrm{BiP}$ was represented in the PM fraction, but to an intensity three-fold lower than in the M fraction. V-type ATPase was present at a comparable levels in the M, LP and PMe fractions. These results indicate that the PM proteins were enriched in the upper phase, which was used in our comparative proteome analysis.

\section{Identification of $N$ deficiency responsive root PM proteins}

A total of 1512 unique peptides corresponding to 215 proteins were identified after subjecting the root PMe fraction to label-free LC-MS. The PCA of the LC-MS data shows that the first principal component was responsible for $75.3 \%$ of the explained variance and the second for the $14.4 \%$ (Supplementary Fig. S4). The clustering of the biological replicates in the scores plot demonstrates that the major variance in the dataset was due to the differences displayed between the contrasting cultivars under $\mathrm{N}$ deficiency, whereas their protein profiles were similar under $\mathrm{N}$-sufficient conditions. About $33 \%$ of the overall identified proteins were predicted to harbor a transmembrane helix (Supplementary Fig. S5), of which 39 proteins harbored at least two transmembrane domains. $\mathrm{N}$ deficiency significantly induced changes in the abundance for 65 of the 215 identified proteins (Table 1).

K-means clustering assembled the differentially changed proteins into seven groups differing in their abundance patterns (Fig. 2). A single protein, namely defensin-like protein was assigned to cluster I, showing the lowest abundance in the sensitive cultivar 'Lambada' under $\mathrm{N}$ sufficiency. Cluster II comprised two proteins decreasing in abundance in 'Lambada' under $\mathrm{N}$ deficiency. Cluster III grouped two proteins displaying a decreased abundance under $\mathrm{N}$ deficiency in the tolerant cultivar 'Topas' and unchanged, low abundance in the sensitive cultivar 'Lambada'. Cluster IV comprised 22 proteins, which showed an increased abundance under $\mathrm{N}$ deficiency in 'Topas', but not in 'Lambada'. The overrepresented functional assignments in this cluster were 'transporters' (12 proteins) and 'protein destination and storage' (three proteins). Two proteins grouped in cluster $\mathrm{V}$ were more abundant in 'Lambada' under both $\mathrm{N}$ regimes. In cluster VI, eight proteins participating in various biological processes, showed a decreased abundance in the tolerant cultivar. Finally, cluster VII included 28 proteins which decreased in both cultivars under $\mathrm{N}$ deficiency. These included proteins assigned to the categories 'transporters' (five proteins), 'signal transduction' (three proteins), 'cell structure' (three proteins) and 'energy' (three proteins). The proteins that were exclusively increased in the 
tolerant genotype 'Topas' under N deficiency (Cluster IV), showing the highest contribution to the variance explained by the first principal component on the PCA (Supplementary Fig. S4) and harboring at least one transmembrane helix, were considered as integral root PM proteins likely involved in potato $\mathrm{N}$ deficiency tolerance.

\section{Candidate proteins involved in the adaptation of potato to $N$ deficiency}

A protein identified as NRT2.1 (accession number- 400031304) increased 8.2-fold in 'Topas' and decreased in 'Lambada'. Three isoforms of the $\mathrm{PM} \mathrm{H}^{+}$-ATPase (400083041, 400065168, 400010497) increased between 1.9- and 4.1-fold in 'Topas', while in 'Lambada' their abundance remained unchanged. Four other proteins also displayed this behavior, including a sugar carrier protein $\mathrm{C}$ (400057709) and two ABC transporters (400018820- ABCB family member, 400046727- ABCA family member). In addition, two proteins belonging to the PM intrinsic protein (PIP) aquaporin subfamily increased in 'Topas' compared to 'Lambada' under $\mathrm{N}$ deficiency. The aquaporin isoforms PIP1;1 (400012780) and PIP1;3 (400032134) were, respectively, four and 2.5 times higher in N-deficient 'Topas', but remained unchanged in 'Lambada' (Fig. 2, marked with asterisks). Additionally, both isoforms were more abundant in 'Topas' (1.6 and 1.8-fold in PIP1;1 and PIP1;3, respectively) than in 'Lambada' under N-sufficient conditions. As aquaporins have not only proved to play an important role in water conductance, but also to facilitate the transport of other small uncharged solutes such as urea or ammonia (Jahn et al., 2004; Loque, Ludewig, Yuan, \& von Wiren, 2005), we further investigated the transcript levels of the PIP1;1 and PIP1;3 genes during $\mathrm{N}$ deficiency and their potential role in $\mathrm{N}$ uptake.

\section{The expression of PIP1;1 decreased in the tolerant cultivar under low $N$}

In the sensitive cultivar, there was no significant difference in thePIP1;1 transcript abundance under both $\mathrm{N}$-sufficient and N-deficient conditions (Fig. 3). In 'Topas', contrary to the protein abundance, $\mathrm{N}$ deficiency caused a two-fold reduction in the PIP1;1 transcript level. The transcription of PIP1;3 was unaffected by N deficiency in both cultivars.

Potato aquaporins StPIP1;1 and StPIP1;3 do not facilitate the transport of ammonia across yeast membranes

In order to test the permeability of aquaporins to solutes such as urea or ammonia, the heterologous expression system $S$. cerevisiae is commonly used. Here we investigated whether StPIP1;1 and StPIP1;3 can channel ammonia across biological membranes thereby potentially directly contributing to $\mathrm{N}$ uptake under $\mathrm{N}$ limiting growth conditions (Fig. 4). We expressed the two StPIP s in a S. cerevisiae deletion mutant strain ( $\Delta$ mep1-3 (-ura/-leu)). This mutant has a deletion in all three ammonium transporter (mep) genes and is therefore unable to grow on medium containing lower than $5 \mathrm{mM}$ ammonium (Marini, Soussi-Boudekou, Vissers, \& Andre, 1997). An additional source of N (e.g. in form of proline) is essential to ensure its growth. As PIP1 aquaporins were repetitively shown to traffic to the PM as PIP1/PIP2 heterodimers and cannot reach the PM membrane when expressed alone (G. P. Bienert et al., 2014; M. D. Bienert, Diehn, Richet, Chaumont, \& Bienert, 2018; Fetter, Van Wilder, Moshelion, \& Chaumont, 2004), StPIPs were either expressed individually or in combination with $Z m P I P 2 ; 5$ in the heterologous expression system. To investigate protein localization in $S$. cerevisiae we used GFP:PIP-fusion proteins of the respective aquaporin expressed in yeast cells. Yeast transformed with GFP:StPIP1;1 or GFP:StPIP1;3alone showed a GFP signal in the internal structures, whereas co-expressed with $Z m P I P 2 ; 5$ GFP was clearly fluorescent in the PM (Supplementary Fig. S6). Neither yeast cells expressing StPIP1;1 or StPIP1;3 alone (Supplementary Fig. S7), nor in combination with $Z m P I P 2 ; 5$ were able to grow on ammonia concentrations below $5 \mathrm{mM}$ (Fig. 5). The expression of the positive control $h A Q P 8$ (Saparov, Liu, Agre, \& Pohl, 2007) complemented the mutant and allowed growth on the medium with low ammonium concentration. This led to the conclusion that StPIP1;1 and StPIP1;3 are not able to channel ammonia.

\section{The absence of PIP1;1 and PIP1;3 leads to a lower $N$ content in the leaves of Arabidopsis}

In Arabidopsis, PIP aquaporins were recently shown to impact on nitrate acquisition by increasing the root hydraulic conductivity (Li et al., 2016). At the amino acid level, the Arabidopsis AtPIP1;3 and AtPIP1;1 share $87.2 \%$ and $85.9 \%$ of sequence identity with the potato StPIP1;3 and StPIP1;1, respectively. When 
Arabidopsis WT was grown underin-vitro based N-deficient conditions, we observed a decrease in the expression of both AtPIP genes (Fig. 5). Subsequently, the Arabidopsis T-DNA insertion mutants Atpip1;1 and Atpip1;3 were used to elucidate the functional properties and potential significance of these two aquaporins in the $\mathrm{N}$ deficiency tolerance. The WT and the T-DNA insertion lines were cultivated on the soil substrate fertilized as described earlier (Pommerrenig et al., 2018) with the exception that $\mathrm{N}$ was supplemented either in limiting $(30 \mathrm{mM})$ or sufficient amounts $(60 \mathrm{mM})$. Under N-sufficient conditions, the shoot fresh weights of the Atpip1;1 and Atpip1;3 mutants were comparable to those of the WT. When the WT and the mutants were grown under $\mathrm{N}$ deficiency, a reduction in the leaf biomass was observed in all plants (Fig. 6) to a similar extent. The $\mathrm{N}$ content of the leaves, which is a representation of $\mathrm{N}$ assimilated by the plant, comprised around 5 to $6 \% \mathrm{~N}$ of the leaf dry weight in all examined plants when $\mathrm{N}$ was supplied in sufficient amounts (Fig. 7A). When the level of $\mathrm{N}$ in the soil was reduced, the WT plants contained $3.4 \%$ of $\mathrm{N}$ in the leaf dry weight. Interestingly, the accumulation of $\mathrm{N}$ was significantly lower in bothpip mutants, where the $\mathrm{N}$ content was as low as 2.4\% in Atpip1;1 and 2.5\% in Atpip1;3 plants. In contrast, the C content increased under $\mathrm{N}$ deficiency similarly in both, the leaves of WT and the pip mutants. In line with these results, the pipmutants displayed a purple coloration of the leaves when the level of $\mathrm{N}$ in the soil was reduced (Fig. 6). Since the purple coloration of Arabidopsis leaves was attributed to anthocyanin accumulation (Kovinich, Kayanja, Chanoca, Otegui, \& Grotewold, 2015), we analyzed the soluble phenylpropanoids levels. The total soluble phenylpropanoid levels of the leaves were similar in all plants when $\mathrm{N}$ was sufficient. As shown in Fig. 7B, under $\mathrm{N}$ deficiency, the content of total phenylpropanoids increased in all plants, but this change was higher in the pipmutants compared to the WT. In agreement with the observed coloration, the same trend was observed in the anthocyanin content, with an average 2.5, 2.1 and 1.7-fold increase in the Atpip1;1, Atpip1;3and WT plants under N deficiency, respectively. These results show that the lack of either AtPIP1;1 or AtPIP1;3 in Arabidopsis leads to an increased susceptibility to $\mathrm{N}$ deficiency, since low $\mathrm{N}$ typically results in increased $\mathrm{C} / \mathrm{N}$ ratios and the accumulation of secondary metabolites, including phenylpropanoids and flavonoids (Fritz, Palacios-Rojas, Feil, \& Stitt, 2006).

\section{Discussion}

\section{$N$ deficiency induced variation in the PM proteome of potato cultivars}

Plants as sessile organisms must constantly adapt their PM composition to properly sense and respond to the variations in their environment. $\mathrm{N}$ deficiency is known to cause changes in the expression of genes participating in the nitrate and ammonia uptake (as reviewed by Kiba and Krapp (2016)), signaling, as well as hormone translocation (O'Brien et al., 2016). Information about the PM protein composition under stress conditions and in particular, in response to $\mathrm{N}$ deficiency, remains however absent for potato. Two potato cultivars that show contrasting N deficiency tolerance (Jozefowicz et al., 2017; Meise et al., 2017; Schum \& Jansen, 2014; Schum et al., 2017) ('Lambada'-sensitive, and 'Topas'-tolerant) formed the basis of the present study to identify PM proteins associated with $\mathrm{N}$ deficiency tolerance. Our study revealed that changes in the root PM composition occur in potato upon $\mathrm{N}$ deficiency. The alterations in the root PM proteome are cultivar specific, as we observed that many proteins respond in a cultivar dependent manner (Clusters I, III, IV, V, Fig. 2). Those proteins which were higher abundant only in the tolerant cultivar under $\mathrm{N}$ deficiency, were considered as potential candidates for improving tolerance to $\mathrm{N}$ shortages in potato.

\section{$P M$ proteins involved in the tolerance of potato to $N$ deficiency}

Proteins functioning in the transport of ions across the membrane were overrepresented in the group of responsive proteins. The abundance of the majority was largely unaffected by $\mathrm{N}$ deficiency in 'Lambada', while increasing in 'Topas'. During N deficiency, four NRT2 genes (Krapp et al., 2011; Lezhneva et al., 2014) and six $A M T$ genes were described to be upregulated in Arabidopsis (Yuan et al., 2007). Probably due to the low abundance of the $\mathrm{N}$ transporters or to the lack of accessible trypsin cleavage sites, only one protein, namely NRT2.1, was identified in our study. NRT2.1 is a major contributor to the high-affinity transport system operating under low levels of external nitrate (Lezhneva et al., 2014; Orsel, Filleur, Fraisier, \& DanielVedele, 2002). The increase in StNRT2.1 protein abundance confirmed that the growth settings used in this study induced the $\mathrm{N}$ deficiency response. In Arabidopsis, $\mathrm{N}$ deficiency induced expression of NRT2.1 in the 
cortex cells of the older part of primary and lateral roots (Wirth et al., 2007). Additionally, it was observed that the expression of AtNRT2.1 increased transiently during short time starvation and decreased to the level slightly higher than before the treatment during prolonged $N$ starvation (Lezhneva et al., 2014). In potato, StNRT2.1 was shown to be higher expressed in the cultivars accumulating more nitrate in the tubers, suggesting that also in potato NRT2.1 is a key factor for nitrate uptake (M'hamdi, Abid, Chikh-Rouhou, Razgallah, \& Hassen, 2016). An increase in the StNRT2.1 abundance under N deficiency may likely be linked to a decrease in the tissue nitrate concentration in 'Topas', inducing the transcriptional upregulation of this high affinity transport system. In 'Lambada' the slight decrease in NRT2.1 abundance might be the consequence of severe $\mathrm{N}$ deficiency, as it was previously described that 'Lambada' absorbs all the $\mathrm{N}$ available in culturing medium faster than 'Topas' (Schum \& Jansen, 2012). The higher abundance of NRT2.1 is probably one of the key factors determining the more tolerant behavior of the cultivar 'Topas' under selected conditions. As the role of NRT2.1 in the nitrate uptake is well characterized (Filleur et al., 2001; Okamoto, Vidmar, \& Glass, 2003; Orsel, Filleur, et al., 2002; Wirth et al., 2007), we thus decided to elucidate proteins which have not yet been associated with contrasting $\mathrm{N}$ deficiency response.

A few other membrane transporters have been identified to be differentially abundant in 'Topas' compared to 'Lambada'. Amongst these are three $\mathrm{PM} \mathrm{H}^{+}$-ATPases (Table 1). These proteins are involved in generating an electrochemical proton gradient across the PM which is the basis for the active transport of various ions and metabolites (Palmgren, 2001). Also, nitrate transport depends on the activity of $\mathrm{PM} \mathrm{H}^{+}$-ATPases (Forde, 2000; Meharg \& Blatt, 1995). All the $\mathrm{H}^{+}$-ATPases identified in this proteome analysis correlate positively in their abundance with that of NRT2.1 (Pearson R $>0.9$, Supplemental Fig. S8), supporting the hypothesis that the sensitive cultivar 'Lambada' responds differentially to $\mathrm{N}$ deficiency in respect to its transport properties at the PM.

Two putative ABC transporters (one of the A subfamily and one of the B subfamily, ABCB) were present in significantly higher amounts in 'Topas' plants exposed to N deficiency (Table 1). In Arabidopsis, the ABCB transporters are known to play a complex role in auxin transport (Blakeslee et al., 2007; Geisler et al., 2005; Hwang et al., 2016) and therefore also in the regulation of root traits (Overvoorde, Fukaki, \& Beeckman, 2010). For instance, AtABCB4 participates in the regulation of root hair elongation (Santelia, Fukao, Martinoia, \& Geisler, 2006), whereas AtABCB1 impacts on lateral root formation (Geisler et al., 2005). In previous experiments, $\mathrm{N}$ deficiency increased the lateral root length in 'Topas', but not in 'Lambada' (Schum \& Jansen, 2013), but so far there is no evidence for the role of ABCB transporters in the auxin transport and in the modification of root architecture in potato.

\section{PIP1;1 and PIP1;3 are indirectly involved in the $N$ uptake}

Interestingly, two aquaporins, StPIP1;1 and StPIP1;3 were induced under N deficiency in the tolerant cultivar 'Topas'. PIPs are channel proteins located in the endoplasmic reticulum and the PM, involved in promoting the transport of water and small neutral solutes such as hydrogen peroxide, carbon dioxide or arsenite across the PM (Dynowski, Schaaf, Loque, Moran, \& Ludewig, 2008; Fetter et al., 2004; Mosa et al., 2012; Uehlein, Lovisolo, Siefritz, \& Kaldenhoff, 2003). Previously, it was shown that certain aquaporin isoforms of the Tonoplast Intrinsic Protein (TIP) family facilitate the transport of ammonia across biological membranes (Jahn et al., 2004; Kirscht et al., 2016; Loque et al., 2005). Here, we tested whether StPIP1;1 and StPIP1;3 are directly involved in $\mathrm{N}$ uptake by sharing the selectivity properties with TIPs. The expression of StPIP1;1 and StPIP1;3 did not increase the growth of yeast mutants under low N supply (Fig. 4), strongly suggesting that these isoforms do not facilitate the transport of ammonia and do not contribute directly to $\mathrm{N}$ uptake in plants.

PIPs were described to be efficient water channels (Maurel et al., 2015) and high PIP expression correlates with high root hydraulic conductivity $\left(L \mathrm{p}_{\mathrm{r}}\right.$ ) (Gambetta et al., 2013; Perrone et al., 2012). Remarkably, it was shown that the local and/or overall nitrate availability influences the $L \mathrm{p}_{\mathrm{r}}$ and thereby, $\mathrm{N}$ uptake by impacting the diffusion of nitrate towards the root surface (Gorska, Ye, Holbrook, \& Zwieniecki, 2008; Ishikawa-Sakurai, Hayashi, \& Murai-Hatano, 2014; G. Li, Tillard, Gojon, \& Maurel, 2016). Generally, it is observed that $\mathrm{N}$ limitation decreases whereas $\mathrm{N}$ resupply stimulates, $L \mathrm{p}_{\mathrm{r}}$ and PIP expression. In contrast 
to these observations, StPIP1;1 and StPIP1;3 protein abundance increased along with StNRT2.1 in the $\mathrm{N}$ deficiency tolerant cultivar 'Topas', whereas the transcript levels decreased for StPIP1;1 and remained unchanged for StPIP1;3 (Fig. 3). Discrepancies between aquaporin transcript and protein levels are not uncommon and might be reasoned by more dynamic mRNA turnover, protein stability or by regulating protein activity by post-translational modifications (Hachez et al., 2012; Velez-Bermudez \& Schmidt, 2014).

In order to further elucidate the possible function of these PIP isoforms in respect to $\mathrm{N}$ deficiency tolerance, we used T-DNA knock-out mutants of the homologous genes of StPIP1;1 and StPIP1;3in Arabidopsis (AtPIP1;1 and AtPIP1;3 ) and investigated these plants in more detail. In WT plants, AtPIP1;1 and AtPIP1;3 transcript levels were downregulated in roots under N-deficient conditions (Fig. 5), which is in line with observations in other plant species in which the transcript levels of PIPs were studied under $\mathrm{N}$ limitation (Ishikawa-Sakurai et al., 2014).

Mass flow of $\mathrm{N}$ towards the root surface, which is stimulated by the close interrelation between transpiration, convection and $L \mathrm{p}_{\mathrm{r}}$, is one of the factors contributing to efficient $\mathrm{N}$ uptake (Tyerman, Wignes, \& Kaiser, 2017). Working with hydroponic- or in vitro -based plant cultivation systems, limits the impact of these parameters on the mass flow towards the roots and might mask the contribution of PIPs to these processes. We established a soil substrate-based cultivation system to overcome this limitation. Interestingly, both insertion lines displayed a higher sensitivity to $\mathrm{N}$ deficiency reflected in their lower $\mathrm{N}$ content in the leaves, as well as in their larger total anthocyanins content (Fig. 6). This indicates that despite their transcriptional downregulation under $\mathrm{N}$ limiting conditions in Arabidopsis, the complete lack of these proteins leads to an increase in $\mathrm{N}$ deficiency sensitivity.

Recently, it was proposed that in Arabidopsis NRT2.1 in its action as a nitrate sensor/transducer, impacts on PIP expression and thereby, on the $L \mathrm{p}_{\mathrm{r}}$ (G. Li et al., 2016). It was shown that PIP1 and PIP2 expression and protein abundance were largely unaffected under both high and low N treatments in the WT, suggesting regulatory events on the post-translational level. PIP expression in the Atnrt2;1 mutant was lower than in the WT, which co-occurred with a decrease in $L$ pr $(\mathrm{G}$. Li et al., 2016). In respect to $\mathrm{N}$ availability, it was shown that despite of a decrease in PIP expression under $\mathrm{N}$ deficiency, $L \mathrm{p}_{\mathrm{r}}$ was rapidly recovered under N resupply (Gloser, Zwieniecki, Orians, \& Holbrook, 2007; Gorska, Ye, et al., 2008; Gorska, Zwieniecka, Holbrook, \& Zwieniecki, 2008). This is probably due to a high degree of post-translational modifications, such as phosphorylation, which enables a rapid response towards changing $\mathrm{N}$ availabilities (di Pietro et al., 2013). It was already argued that aquaporins activity is locally regulated by the $\mathrm{N}$ availability of roots (Gorska, Ye, et al., 2008; Ishikawa-Sakurai et al., 2014). Therefore, it is conceivable, that irrespectively of an overall transcriptional downregulation of AtPIP1;1 and AtPIP1;3 under N limitation in Arabidopsis, the protein is of importance to sustain local or overall $L \mathrm{p}_{\mathrm{r}}$ at places with higher $\mathrm{N}$ availability or under prolonged $\mathrm{N}$ deficiency, respectively. Furthermore, a higher level of certain PIP isoforms might be of advantage under $\mathrm{N}$-deficient conditions to enable rapid changes in protein activity.

We observed a concurrently increased abundance of StNRT2.1 with StPIP1;1 and StPIP1;3 in the tolerant potato cultivar. This indicates that in the cultivar 'Topas', these two PIP aquaporins might be in their inactive state, awaiting their local and rapid activation, to ensure efficient $\mathrm{N}$ delivery to the root surface. Another explanation might be, that StPIP1;1 and StPIP1;3 are important isoforms which ensure a steady state mass flow of water towards the root under $\mathrm{N}$ limiting conditions, which points towards a function of these PIPs in contributing to the $\mathrm{N}$ deficiency tolerance in cultivar 'Topas'.

In conclusion, $\mathrm{N}$ limitation has been shown to modify the potato root PM proteome, and clear differences have been identified between the two varieties contrasting in their response to $\mathrm{N}$ deficiency. It has been possible to identify several candidate proteins likely involved in the mechanisms underlying $\mathrm{N}$ deficiency tolerance. Our data suggest that the increased abundance of StPIP1;1 and StPIP1;3 together with StNRT2.1 is one of the factors contributing to $\mathrm{N}$ deficiency tolerance in potato. In addition, evidence is presented that AtPIP1;1 and AtPIP1;3 interplay with efficient $\mathrm{N}$ uptake under $\mathrm{N}$ limiting conditions in Arabidopsis, which is in accordance with the working model proposed previously (G. Li et al., 2016; Tyerman et al., 2017). To the best of our knowledge, it has not been reported previously, that the lack of individual PIP aquaporins results 
in a decrease in $\mathrm{N}$ deficiency tolerance.

\section{Acknowledgments}

We thank Dr. Twan Rutten for assistance with confocal microscopy. We gratefully acknowledge the technical assistance of Petra Linow and Barbara Kettig. We kindly thank Prof. Anna Maria Marini for providing the $\Delta \mu \epsilon \pi 1-3$ (-ura/-leu) yeast strain (Université Libre de Bruxelles).

\section{References}

Alexandersson, E., Danielson, J. A. H., Rade, J., Moparthi, V. K., Fontes, M., Kjellbom, P., \& Johanson, U. (2010). Transcriptional regulation of aquaporins in accessions of Arabidopsis in response to drought stress. Plant Journal, 61 (4), 650-660.

Alexandersson, E., Saalbach, G., Larsson, C., \& Kjellbom, P. (2004). Arabidopsis plasma membrane proteomics identifies components of transport, signal transduction and membrane trafficking. Plant and Cell Physiology, 45 (11), 1543-1556.

Alonso, J. M., Stepanova, A. N., Leisse, T. J., Kim, C. J., Chen, H. M., Shinn, P., . . Ecker, J. R. (2003). Genome-wide insertional mutagenesis of Arabidopsis thaliana . Science, 301 (5633), 653-657.

Amme, S., Rutten, T., Melzer, M., Sonsmann, G., Vissers, J. P. C., Schlesier, B., . . Mock, H. P. (2005). Proteome analysis to define cellular functions of tobacco leaf trichomes. Comparative Biochemistry and Physiology A:Molecular 83 Integrative Physiology, 141 (3), 2508-2518.

Arend, D., Lange, M., Chen, J. B., Colmsee, C., Flemming, S., Hecht, D., \& Scholz, U. (2014). e!DAL - a framework to store, share and publish research data. Bmc Bioinformatics, 15 , 214.

Barbier-Brygoo, H., De Angeli, A., Filleur, S., Frachisse, J. M., Gambale, F., Thomine, S., \& Wege, S. (2011). Anion channels/transporters in plants: from molecular bases to regulatory networks. Annual Review of Plant Biology, 62 , 25-51.

Barkla, J. B., \& Pantoja, O. (2010). Plasma membrane and abiotic stress. Plant Cell Monographs, 19 , 457-470.

Bienert, G. P., Heinen, R. B., Berny, M. C., \& Chaumont, F. (2014). Maize plasma membrane aquaporin ZmPIP2;5, but not ZmPIP1;2, facilitates transmembrane diffusion of hydrogen peroxide. Biochimica et Biophysica Acta, 1838 (1 B), 216-222.

Bienert, M. D., Diehn, T. A., Richet, N., Chaumont, F., \& Bienert, G. P. (2018). Heterotetramerization of plant PIP1 and PIP2 aquaporins is an evolutionary ancient feature to guide PIP1 plasma membrane localization and function. Frontiers in Plant Science, 9 , 382.

Blakeslee, J. J., Bandyopadhyay, A., Lee, O. R., Mravec, J., Titapiwatanakun, B., Sauer, M., . . Murphy, A. S. (2007). Interactions among PIN-FORMED and P-glycoprotein auxin transporters in Arabidopsis.Plant Cell, 19 (1), 131-147.

Bradford, M. M. (1976). Rapid and sensitive method for quantitation of microgram quantities of protein utilizing principle of protein-dye binding. Analytical Biochemistry, 72 (1-2), 248-254.

Cambouris, A. N., Zebarth, B. J., Nolin, M. C., \& Laverdiere, M. R. (2008). Apparent fertilizer nitrogen recovery and residual soil nitrate under continuous potato cropping: Effect of $\mathrm{N}$ fertilization rate and timing. Canadian Journal of Soil Science, 88 (5), 813-825.

Chao, D. Y., \& Lin, H. X. (2015). Transport solution in rice variations. Nature Plants, 1 (7).

Cheng, Y., Qi, Y., Zhu, Q., Chen, X., Wang, N., Zhao, X., . . . Zhang, W. (2009). New changes in the plasma-membrane-associated proteome of rice roots under salt stress. Proteomics, 9 (11), 3100-3114. 
Conesa, A., \& Gotz, S. (2008). Blast2GO: A comprehensive suite for functional analysis in plant genomics. International Journal of Plant Genomics, 2008, 619832.

Cordwell, S. J., \& Thingholm, T. E. (2010). Technologies for plasma membrane proteomics. Proteomics, 10 (4), 611-627.

Czechowski, T., Stitt, M., Altmann, T., Udvardi, M. K., \& Scheible, W. R. (2005). Genome-wide identification and testing of superior reference genes for transcript normalization in Arabidopsis. Plant Physiology, 139 (1), 5-17.

di Pietro, M., Vialaret, J., Li, G. W., Hem, S., Prado, K., Rossignol, M., . . Santoni, V. (2013). Coordinated post-translational responses of aquaporins to abiotic and nutritional stimuli in Arabidopsis roots. Molecular 83 Cellular Proteomics, 12 (12), 3886-3897.

Dynowski, M., Schaaf, G., Loque, D., Moran, O., \& Ludewig, U. (2008). Plant plasma membrane water channels conduct the signalling molecule H2O2. The Biochemical Journal, 414 (1), 53-61.

Fetter, K., Van Wilder, V., Moshelion, M., \& Chaumont, F. (2004). Interactions between plasma membrane aquaporins modulate their water channel activity. Plant Cell, 16 (1), 215-228.

Filleur, S., Dorbe, M. F., Cerezo, M., Orsel, M., Granier, F., Gojon, A., \& Daniel-Vedele, F. (2001). An arabidopsis T-DNA mutant affected in Nrt2 genes is impaired in nitrate uptake. Febs Letters, 489 (2-3), $220-224$.

Forde, B. G. (2000). Nitrate transporters in plants: structure, function and regulation. Biochimica et Biophysica Acta-Biomembranes, 1465 (1-2), 219-235.

Fritz, C., Palacios-Rojas, N., Feil, R., \& Stitt, M. (2006). Regulation of secondary metabolism by the carbonnitrogen status in tobacco: nitrate inhibits large sectors of phenylpropanoid metabolism. The Plant Journal, $46(4), 533-548$.

Frommer, W. B., Kwart, M., Hirner, B., Fischer, W. N., Hummel, S., \& Ninnemann, O. (1994). Transporters for nitrogenous compounds in plants.Plant Molecular Biology, 26 (5), 1651-1670.

Gambetta, G. A., Fei, J., Rost, T. L., Knipfer, T., Matthews, M. A., Shackel, K. A., . . McElrone, A. J. (2013). Water uptake along the length of grapevine fine roots: developmental anatomy, tissue-specific aquaporin expression, and pathways of water transport. Plant Physiology, 163 (3), 1254-1265.

Garnett, T., Plett, D., Heuer, S., \& Okamoto, M. (2015). Genetic approaches to enhancing nitrogen-use efficiency (NUE) in cereals: challenges and future directions. Functional Plant Biology, 42 (10), 921-941.

Geisler, M., Blakeslee, J. J., Bouchard, R., Lee, O. R., Vincenzetti, V., Bandyopadhyay, A., . . Martinoia, E. (2005). Cellular efflux of auxin catalyzed by the Arabidopsis MDR/PGP transporter AtPGP1. The Plant Journal, 44 (2), 179-194.

Gloser, V., Zwieniecki, M. A., Orians, C. M., \& Holbrook, N. M. (2007). Dynamic changes in root hydraulic properties in response to nitrate availability. Journal of Experimental Botany, 58 (10), 2409-2415.

Good, A. G., Shrawat, A. K., \& Muench, D. G. (2004). Can less yield more? Is reducing nutrient input into the environment compatible with maintaining crop production? Trends in Plant Science, 9 (12), 597-605.

Gorska, A., Ye, Q., Holbrook, N. M., \& Zwieniecki, M. A. (2008). Nitrate control of root hydraulic properties in plants: Translating local information to whole plant response. Plant Physiology, 148 (2), 1159-1167.

Gorska, A., Zwieniecka, A., Holbrook, N. M., \& Zwieniecki, M. A. (2008). Nitrate induction of root hydraulic conductivity in maize is not correlated with aquaporin expression. Planta, 228 (6), 989-998.

Gronnier, J., Gerbeau-Pissot, P., Germain, V., Mongrand, S., \& Simon-Plas, F. (2018). Divide and rule: Plant plasma membrane organization. Trends in Plant Science, 23 (10), 899-917. 
Guo, J., Wang, Y., Fan, T., Chen, X., \& Cui, Z. (2016). Designing corn management strategies for high yield and high nitrogen use efficiency.Agronomy Journal, 108 (2), 922-929.

Hachez, C., Veselov, D., Ye, Q., Reinhardt, H., Knipfer, T., Fricke, W., \& Chaumont, F. (2012). Short-term control of maize cell and root water permeability through plasma membrane aquaporin isoforms. Plant Cell Es Environment, 35 (1), 185-198.

Hajari, E., Snyman, S. J., \& Watt, M. P. (2015). Nitrogen use efficiency of sugarcane (Saccharum spp .) varieties under in vitro conditions with varied N supply. Plant Cell Tissue and Organ Culture, 122 (1), 21-29.

Hamann, T., \& Moller, B. L. (2007). Improved cloning and expression of cytochrome P450s and cytochrome P450 reductase in yeast. Protein Expression and Purification, 56 (1), 121-127.

Hashimoto, M., Toorchi, M., Matsushita, K., Iwasaki, Y., \& Komatsu, S. (2009). Proteome analysis of rice root plasma membrane and detection of cold stress responsive proteins. Protein and Peptide Letters, 16 (6), 685-697.

Hwang, J. U., Song, W. Y., Hong, D., Ko, D., Yamaoka, Y., Jang, S., . . Lee, Y. (2016). Plant ABC transporters enable many unique aspects of a terrestrial plant's lifestyle. Molecular plant, 9 (3), 338-355.

Hynek, R., Svensson, B., Jensen, O. N., Barkholt, V., \& Finnie, C. (2006). Enrichment and identification of integral membrane proteins from barley aleurone layers by reversed-phase chromatography, SDS-PAGE, and LC-MS/MS. Journal of Proteome Research, 5 (11), 3105-3113.

Ishikawa-Sakurai, J., Hayashi, H., \& Murai-Hatano, M. (2014). Nitrogen availability affects hydraulic conductivity of rice roots, possibly through changes in aquaporin gene expression. Plant and Soil, 379 (1-2), 289-300.

Iwama, K. (2008). Physiology of the potato: New insights into root system and repercussions for crop management. Potato Research, 51 (3-4), 333-353.

Jahn, T. P., Moller, A. L. B., Zeuthen, T., Holm, L. M., Klaerke, D. A., Mohsin, B., . . Schjoerring, J. K. (2004). Aquaporin homologues in plants and mammals transport ammonia. Febs Letters, 574 (1-3), 31-36.

Jozefowicz, A. M., Hartmann, A., Matros, A., Schum, A., \& Mock, H. P. (2017). Nitrogen deficiency induced alterations in the root proteome of a pair of potato (Solanum tuberosum L. ) varieties contrasting for their response to low N. Proteomics, 17 (23-24).

Jozefowicz, A. M., Matros, A., Witzel, K., \& Mock, H. P. (2018). Mini-scale isolation and preparation of plasma membrane proteins from potato roots for LC/MS analysis. Methods in Molecular Biology, 1696 , 195-204.

Ju, C. X., Buresh, R. J., Wang, Z. Q., Zhang, H., Liu, L. J., Yang, J. C., \& Zhang, J. H. (2015). Root and shoot traits for rice varieties with higher grain yield and higher nitrogen use efficiency at lower nitrogen rates application. Field Crops Research, 175, 47-55.

Kiba, T., \& Krapp, A. (2016). Plant nitrogen acquisition under low availability: Regulation of uptake and root architecture. Plant and Cell Physiology, 57 (4), 707-714.

Kirscht, A., Kaptan, S. S., Bienert, G. P., Chaumont, F., Nissen, P., de Groot, B. L., . . Johanson, U. (2016). Crystal structure of an ammonia-permeable aquaporin. Plos Biology, 14 (3).

Komatsu, S. (2008). Plasma membrane proteome in Arabidopsis and rice.Proteomics, 8 (19), 4137-4145.

Komatsu, S., Wada, T., Abalea, Y., Nouri, M. Z., Nanjo, Y., Nakayama, N., . . . Furukawa, K. (2009). Analysis of plasma membrane proteome in Soybean and application to flooding stress response. Journal of Proteome Research, 8 (10), 4487-4499.

Kovinich, N., Kayanja, G., Chanoca, A., Otegui, M. S., \& Grotewold, E. (2015). Abiotic stresses induce different localizations of anthocyanins in Arabidopsis. Plant Signaling \&3 Behavior, 10 (7), e1027850. 
Krapp, A., Berthome, R., Orsel, M., Mercey-Boutet, S., Yu, A., Castaings, L., . . Daniel-Vedele, F. (2011). Arabidopsis roots and shoots show distinct temporal adaptation patterns toward nitrogen starvation. Plant Physiology, 157 (3), 1255-1282.

Krogh, A., Larsson, B., von Heijne, G., \& Sonnhammer, E. L. L. (2001). Predicting transmembrane protein topology with a hidden Markov model: Application to complete genomes. Journal of Molecular Biology, 305 (3), $567-580$.

Laemmli, U. K. (1970). Cleavage of structural proteins during assembly of head of Bacteriophage-T4. Nature, 227 (5259), 680-685.

Leran, S., Varala, K., Boyer, J. C., Chiurazzi, M., Crawford, N., Daniel-Vedele, F., . . Lacombe, B. (2014). A unified nomenclature of NITRATE TRANSPORTER 1/PEPTIDE TRANSPORTER family members in plants. Trends in Plant Science, 19 (1), 5-9.

Lezhneva, L., Kiba, T., Feria-Bourrellier, A. B., Lafouge, F., Boutet-Mercey, S., Zoufan, P., . . Krapp, A. (2014). The Arabidopsis nitrate transporter NRT2.5 plays a role in nitrate acquisition and remobilization in nitrogen-starved plants. The Plant Journal, 80 (2), 230-241.

Li, G., Tillard, P., Gojon, A., \& Maurel, C. (2016). Dual regulation of root hydraulic conductivity and plasma membrane aquaporins by plant nitrate accumulation and high-affinity nitrate transporter NRT2.1.Plant and Cell Physiology, 57 (4), 733-742.

Li, P. C., Chen, F. J., Cai, H. G., Liu, J. C., Pan, Q. C., Liu, Z. G., . . Yuan, L. X. (2015). A genetic relationship between nitrogen use efficiency and seedling root traits in maize as revealed by QTL analysis. Journal of Experimental Botany, 66 (11), 3175-3188.

Loque, D., Ludewig, U., Yuan, L., \& von Wiren, N. (2005). Tonoplast intrinsic proteins AtTIP2;1 and AtTIP2;3 facilitate NH3 transport into the vacuole. Plant Physiology, 137 (2), 671-680.

Loque, D., \& von Wiren, N. (2004). Regulatory levels for the transport of ammonium in plant roots. Journal of Experimental Botany, 55 (401), 1293-1305.

M'hamdi, M., Abid, G., Chikh-Rouhou, H., Razgallah, N., \& Hassen, A. (2016). Effect of genotype and growing season on nitrate accumulation and expression patterns of nitrate transporter genes in potato (Solanum tuberosum L .). Archives of Agronomy and Soil Science, 62 (11), 1508-1520.

Marini, A. M., Soussi-Boudekou, S., Vissers, S., \& Andre, B. (1997). A family of ammonium transporters in Saccharomyces cerevisiae. Molecular and Cellular Biology, 17 (8), 4282-4293.

Masclaux-Daubresse, C., Daniel-Vedele, F., Dechorgnat, J., Chardon, F., Gaufichon, L., \& Suzuki, A. (2010). Nitrogen uptake, assimilation and remobilization in plants: challenges for sustainable and productive agriculture. Annals of Botany, 105 (7), 1141-1157.

Maurel, C., Boursiac, Y., Luu, D. T., Santoni, V., Shahzad, Z., \& Verdoucq, L. (2015). Aquaporins in plants. Physiological Reviews, 95 (4), 1321-1358.

Meharg, A. A., \& Blatt, M. R. (1995). NO3- transport across the plasma-membrane of Arabidopsis thaliana root hairs - kinetic control by ph and membrane voltage. Journal of Membrane Biology, 145 (1), 49-66.

Meise, P., Jozefowicz, A. M., Uptmoor, R., Mock, H.-P., Ordon, F., \& Schum, A. (2017). Comparative shoot proteome analysis of two potato (Solanum tuberosum L.) genotypes contrasting in nitrogen deficiency responses in vitro. Journal of Proteomics, 166 , 68-82.

Mosa, K. A., Kumar, K., Chhikara, S., Mcdermott, J., Liu, Z. J., Musante, C., . . Dhankher, O. P. (2012). Members of rice plasma membrane intrinsic proteins subfamily are involved in arsenite permeability and tolerance in plants. Transgenic Research, 21 (6), 1265-1277. 
Negi, J., Matsuda, O., Nagasawa, T., Oba, Y., Takahashi, H., Kawai-Yamada, M., . . Iba, K. (2008). CO2 regulator SLAC1 and its homologues are essential for anion homeostasis in plant cells. Nature, 452 (7186), 483-486.

Nicot, N., Hausman, J. F., Hoffmann, L., \& Evers, D. (2005). Housekeeping gene selection for real-time RTPCR normalization in potato during biotic and abiotic stress. Journal of Experimental Botany, 56 (421), 2907-2914.

Nour-Eldin, H. H., Hansen, B. G., Norholm, M. H., Jensen, J. K., \& Halkier, B. A. (2006). Advancing uracilexcision based cloning towards an ideal technique for cloning PCR fragments. Nucleic Acids Research, 34 (18), e122.

O’Brien, J. A., Vega, A., Bouguyon, E., Krouk, G., Gojon, A., Coruzzi, G., \& Gutierrez, R. A. (2016). Nitrate transport, sensing, and responses in plants. Molecular plant, 9 (6), 837-856.

Okamoto, M., Vidmar, J. J., \& Glass, A. D. (2003). Regulation of NRT1 and NRT2 gene families of Arabidopsis thaliana : responses to nitrate provision. Plant and Cell Physiollogy, 44 (3), 304-317.

Orsel, M., Filleur, S., Fraisier, V., \& Daniel-Vedele, F. (2002). Nitrate transport in plants: which gene and which control? Journal of Experimental Botany, 53 (370), 825-833.

Orsel, M., Krapp, A., \& Daniel-Vedele, F. (2002). Analysis of the NRT2 nitrate transporter family in Arabidopsis. Structure and gene expression. Plant Physiology, 129 (2), 886-896.

Overvoorde, P., Fukaki, H., \& Beeckman, T. (2010). Auxin control of root development. Cold Spring Harb Perspect Biol, 2 (6), a001537.

Palmgren, M. G. (2001). Plant plasma membrane H+-ATPases: Powerhouses for nutrient uptake. Annual Review of Plant Physiology and Plant Molecular Biology, 52 , 817-845.

Perrone, I., Gambino, G., Chitarra, W., Vitali, M., Pagliarani, C., Riccomagno, N., . . Lovisolo, C. (2012). The grapevine root-specific aquaporin VvPIP2;4N controls root hydraulic conductance and leaf gas exchange under well-watered conditions but not under water stress.Plant Physiology, 160 (2), 965-977.

Pommerrenig, B., Junker, A., Abreu, I., Bieber, A., Fuge, J., Willner, E., . . B Bienert, G. P. (2018). Identification of Rapeseed (Brassica napus) cultivars with a high tolerance to boron-deficient conditions. Frontiers in Plant Science, 9 , 1142.

Ray, S., Kassan, A., Busija, A. R., Rangamani, P., \& Patel, H. H. (2016). The plasma membrane as a capacitor for energy and metabolism.American Journal of Physiology-Cell Physiology, 310 (3), C181-C192.

Rosso, M. G., Li, Y., Strizhov, N., Reiss, B., Dekker, K., \& Weisshaar, B. (2003). An Arabidopsis thaliana TDNA mutagenized population (GABI-Kat) for flanking sequence tag-based reverse genetics. Plant Molecular Biology, 53 (1), 247-259.

Santelia, D., Fukao, Y., Martinoia, E., \& Geisler, M. (2006). MDR-like ABC transporter AtPGP4 is involved in auxin-mediated lateral root and root hair development. Plant and Cell Physiology, 47, S184-S184.

Saparov, S. M., Liu, K., Agre, P., \& Pohl, P. (2007). Fast and selective ammonia transport by aquaporin-8. Journal of Biological Chemistry, 282 (8), 5296-5301.

Schlesier, B., Breton, F., \& Mock, H. P. (2003). A hydroponic culture system for growing Arabidopsis thaliana plantlets under sterile conditions. Plant Molecular Biology Reporter, 21 (4), 449-456.

Schum, A., \& Jansen, G. (2012). Physiological response to nitrogen deficiency stress of in vitro grown potato genotypes. Paper presented at the VIIth International Symposium on In Vitro Culture and Horticultural Breeding, Ghent, Belgium. 
Schum, A., \& Jansen, G. (2013, 15 - 19. sept. 2013).Determination of phenotypic plasticity of in vitro grown potatoes in response to abiotic stress conditions - assessment of nitrogen deficiency effects. Paper presented at the Potato agrophysiology 2013, Prague.

Schum, A., \& Jansen, G. (2014). In vitro method for early evaluation of nitrogen use efficiency associated traits in potato. Journal of Applied Botany and Food Quality, 87, 256-264.

Schum, A., Meise, P., Jansen, G., Seddig, S., \& Ordon, F. (2017). Evaluation of nitrogen efficiency associated traits of starch potato cultivars under in vitro conditions. Plant Cell Tissue and Organ Culture, 130 (3), 651-665.

Shaviv, A., \& Mikkelsen, R. L. (1993). Controlled-release fertilizers to increase efficiency of nutrient use and minimize environmental degradation - a review. Fertilizer Research, 35 (1-2), 1-12.

Tilman, D. (1999). Global environmental impacts of agricultural expansion: the need for sustainable and efficient practices.Proceedings of the National Academy of Sciences of the United States of America, 96 (11), 5995-6000.

Tyanova, S., Temu, T., Sinitcyn, P., Carlson, A., Hein, M. Y., Geiger, T., . . . Cox, J. (2016). The Perseus computational platform for comprehensive analysis of (prote)omics data. Nature Methods, 13 (9), 731-740.

Tyerman, S. D., Wignes, J. A., \& Kaiser, B. N. (2017). Root hydraulic and aquaporin responses to N availability. In F. Chaumont \& S. D. Tyerman (Eds.), Plant Aquaporins: From Transport to Signaling(pp. 207-236). Cham: Springer International Publishing.

Uehlein, N., Lovisolo, C., Siefritz, F., \& Kaldenhoff, R. (2003). The tobacco aquaporin NtAQP1 is a membrane CO2 pore with physiological functions. Nature, 425 (6959), 734-737.

Velez-Bermudez, I. C., \& Schmidt, W. (2014). The conundrum of discordant protein and mRNA expression. Are plants special? Frontiers in Plant Science, 5 , 619.

Venkatesh, J., Yu, J. W., \& Park, S. W. (2013). Genome-wide analysis and expression profiling of the Solanum tuberosum aquaporins.Plant Physiology and Biochemistry, 73 , 392-404.

Voothuluru, P., Anderson, J. C., Sharp, R. E., \& Peck, S. C. (2016). Plasma membrane proteomics in the maize primary root growth zone: novel insights into root growth adaptation to water stress. Plant Cell $\mathscr{E}$ Environment, 39 (9), 2043-2054.

Wirth, J., Chopin, F., Santoni, V., Viennois, G., Tillard, P., Krapp, A., . . Gojon, A. (2007). Regulation of root nitrate uptake at the NRT2.1 protein level in Arabidopsis thaliana. Journal of Biological Chemistry, 282 (32), 23541-23552.

Witzel, K., Matros, A., Moller, A. L. B., Ramireddy, E., Finnie, C., Peukert, M., . . Mock, H. P. (2018). Plasma membrane proteome analysis identifies a role of barley membrane steroid binding protein in root architecture response to salinity. Plant Cell \& Environment, 41 (6), 1311-1330.

Xu, D. R., Dhiman, R., Garibay, A., Mock, H. P., Leister, D., \& Kleine, T. (2019). Cellulose defects in the Arabidopsis secondary cell wall promote early chloroplast development. The Plant Journal, 101 (1), 156-170.

Xu, X., Pan, S. K., Cheng, S. F., Zhang, B., Mu, D. S., Ni, P. X., . . Consortiu, P. G. S. (2011). Genome sequence and analysis of the tuber crop potato. Nature, 475 (7355), 189-194.

Yuan, L., Loque, D., Kojima, S., Rauch, S., Ishiyama, K., Inoue, E., . . . von Wiren, N. (2007). The organization of high-affinity ammonium uptake in Arabidopsis roots depends on the spatial arrangement and biochemical properties of AMT1-type transporters. Plant Cell, 19 (8), 2636-2652.

\section{Tables}

Table 1 . Label-free quantification of the set of 65 proteins showing significantly altered abundance in the potato root PM induced by nitrogen $(\mathrm{N})$ deficiency treatment. The proteins were clustered according to 
their genotype- and treatment-specific abundance into seven groups (see Fig. 2). Their accession number, description, functional classification (where known) and their predicted content of transmembrane helices as well as the abundance ratios are given. Accession numbers are given without the PGSC003DMT prefix. Abbreviations: LamC- Lambada N sufficient, LamS- Lambada N deficient, TopC- Topas N sufficient, TopSTopas N deficient, TMH - Transmembrane helices. Full details of the protein identification are stored together with raw data.

\begin{tabular}{|c|c|c|c|}
\hline Accession & Description & Function & $\mathrm{TMH}$ \\
\hline Cluster 1 & Cluster 1 & Cluster 1 & Cluster \\
\hline 400039130 & Defensin-like protein & disease/defence & 1 \\
\hline Cluster 2 & Cluster 2 & Cluster 2 & Cluster \\
\hline 400079443 & GLOBIN domain-containing protein & unclassified & 0 \\
\hline 400083124 & GSDH domain-containing protein & unclassified & 1 \\
\hline Cluster 3 & Cluster 3 & Cluster 3 & Cluster \\
\hline 400005571 & Glutathione S-transferase-like protein & disease/defence & 0 \\
\hline 400040518 & Putative cinnamyl alcohol dehydrogenase & secondary metabolism & 0 \\
\hline Cluster 4 & Cluster 4 & Cluster 4 & Cluster \\
\hline 400035262 & Sucrose synthase & metabolism & 0 \\
\hline 400047710 & Luminal-binding protein 5 & protein destination and storage & 1 \\
\hline 400035380 & ADP,ATP carrier protein & transporters & 3 \\
\hline 400018820 & Putative ABC transporter B family member & transporters & 9 \\
\hline 400025670 & RING-type E3 ubiquitin transferase & protein destination and storage & 0 \\
\hline 400083041 & Plasma membrane ATPase & transporters & 8 \\
\hline 400019462 & Uncharacterized protein & unclassified & 0 \\
\hline 400036847 & Pyrophosphate- energized vacuolar membrane proton pump 1 & transporters & 13 \\
\hline 400031304 & High-affinity nitrate transporter 2.1 & transporters & 11 \\
\hline 400005236 & Hypersensitive induced response protein 2 like & disease/defence & 0 \\
\hline 400001904 & Ras-related protein RABG3f like & intracellular traffic & 0 \\
\hline 400057709 & Sugar carrier protein $\mathrm{C}$ & transporters & 12 \\
\hline 400029027 & Tetraspanin- 8 & disease/defence & 4 \\
\hline 400027156 & Ubiquitin & protein destination and storage & 0 \\
\hline 400046727 & Putative ABC transporter A family member & transporters & 6 \\
\hline 400046278 & Calmodulin- $2 / 4$ & signal transduction & 0 \\
\hline 400032134 & Aquaporin PIP1;3 & transporters & 6 \\
\hline 400065168 & Plasma membrane ATPase & transporters & 8 \\
\hline 400036643 & Transmembrane protein & unclassified & 6 \\
\hline 400012780 & Aquaporin PIP1;1 & transporters & 6 \\
\hline 400010497 & Plasma membrane ATPase & transporters & 8 \\
\hline 400005889 & CSC1-like protein & transporters & 10 \\
\hline Cluster 5 & Cluster 5 & Cluster 5 & Cluster \\
\hline 400004106 & 1-phosphatidylinositol phosphodiesterase & metabolism & 0 \\
\hline 400051789 & AvrRpt-cleavage domain-containing protein & unclassified & 0 \\
\hline Cluster 6 & Cluster 6 & Cluster 6 & Cluster \\
\hline 400073713 & 70-kD heat shock protein & disease/defence & 0 \\
\hline 400076528 & GTP-binding nuclear protein & intracellular traffic & 0 \\
\hline 400016422 & 14-3-3 protein & unclassified & 0 \\
\hline 400075291 & $40 \mathrm{~S}$ ribosomal protein $\mathrm{S} 6$ & protein synthesis & 0 \\
\hline 400014945 & Putative vacuolar proton ATPase subunit E & transporters & 0 \\
\hline 400068704 & Vacuolar proton pump subunit B & transporters & 0 \\
\hline 400004125 & Peptidyl-prolyl cis-trans isomerase & protein destination and storage & 0 \\
\hline 400033202 & Fasciclin-like arabinogalactan protein & cell structure & 0 \\
\hline
\end{tabular}




\begin{tabular}{llll}
\hline Accession & Description & Function & TMH \\
\hline Cluster 7 & Cluster 7 & Cluster 7 & Cluster \\
400047481 & Actin & cell structure & 0 \\
400058342 & CASP-like protein & unclassified & 4 \\
400024318 & FAS1 domain-containing protein & unclassified & 0 \\
400062832 & GSDH domain-containing protein & cell structure & 0 \\
400022574 & Alpha-tubulin & transporters & 0 \\
400070407 & ATP synthase D chain & unclassified & 0 \\
400035497 & Putative plant intracellular Ras-group-related LRR protein 4-like & 0 \\
400078507 & ATP synthase subunit beta & transporters & 0 \\
400023732 & Protein kinase domain-containing protein & signal transduction & 2 \\
400010174 & Actin 1 & cell structure & 0 \\
400058377 & Pollen-specific lysine-rich protein SBgLR & unclassified & 0 \\
400039213 & Protein kinase domain-containing protein & signal transduction & 2 \\
400073467 & Phospholipase D & metabolism & 0 \\
400045607 & Protein kinase domain-containing protein & signal transduction & 1 \\
400041634 & 14-3-3 protein & unclassified & 0 \\
400007182 & Dihydrolipoamide Dehydrogenase & energy & 0 \\
400079310 & 60S ribosomal protein L13 & protein synthesis & 0 \\
400012216 & Cupredoxin superfamily protein isoform 1 & unclassified & 1 \\
400057418 & Glycerophosphodiesterase-like protein & metabolism & 1 \\
400008687 & 60S ribosomal protein L12 & protein synthesis & 0 \\
400061841 & Xyloglucan endotransglucosylase/hydrolase & cell growth/division & 0 \\
400036347 & PLAT domain-containing protein & disease/defence & 1 \\
400006894 & Fructose-bisphosphate aldolase & energy & 0 \\
400010366 & V-type proton ATPase subunit E2 & transporters & 0 \\
400013297 & Putative patellin-2-like & cell growth/division & 0 \\
400008800 & V-type proton ATPase subunit B2 & transporters & 0 \\
400044217 & Malate dehydrogenase & energy & 0 \\
400074197 & Vacuolar H+-ATPase A1 subunit isoform & transporters & 0 \\
\hline
\end{tabular}

\section{Figure legends}

Figure 1. Enrichment for plasma membrane (PM) proteins. A-Western blot analysis of the sub-cellular fractions obtained from the roots of 'Topas' plants grown under nitrogen (N)-sufficient conditions. The compartment-specific marker proteins were: $\mathrm{H}^{+}$-ATPase (PM marker), VDAC (mitochondrial), BiP (ER), MDAR (cytosolic), V-ATPase (vacuolar). Abbreviations are used as follows, C- crude extract, S- soluble fraction, M- microsomal fraction, LP- lower phase, PMe- plasma membrane fraction.

Figure 2. Heat map representation of proteins with differential abundance (p-value $<0.05$, fold change $>1.5$ ) in the two potato cultivars contrasting in their nitrogen $(\mathrm{N})$ deficiency response, grown under either sufficient or deficient $\mathrm{N}$ conditions. According to the K-means algorithm, the proteins formed seven clusters. Relative abundance has been color-coded following Z-score normalization. Each column represents one treatment. Abbreviation used: HN- N sufficient treatment, LN- N deficient treatment. The aquaporin proteins PIP1;1 and PIP1;3 are marked with an asterisk each.

Figure 3. Effect on nitrogen (N) deficiency on theStPIP1;1 and StPIP1;3 transcript abundances in roots of the potato cultivars 'Lambada' and 'Topas'. The expression of genes was quantified using qRT-PCR. The expression of genes was measured using qRT-PCR. Bars (black: N-sufficient, white: N-deficient conditions) labeled by a different letter indicate statistically significant differences $(\mathrm{p}<0.05)$, error bars represent \pm SD.

Figure 4. The ammonium transport ability of PIP1;1 and PIP1;3 studied in yeast by a growth comple- 
mentation assay. The $\Delta$ mep1-3mutant was co-transformed with the combination of empty vector (EV) and indicated PIP cDNA. Cultures spotted on the medium containing indicated amount of ammonium or $0.2 \%$ proline (positive control) as nitrogen sources. The growth of the transformants was recorded after 8-10 days of incubation at $30{ }^{\circ} \mathrm{C}$. Displayed image represents a group of images assembled from different growth conditions.

Figure 5. Effect on nitrogen $(\mathrm{N})$ deficiency on theAtPIP1;1 and AtPIP1;3 transcript abundances in the roots of in-vitro grown Arabidopsis WT plants. The expression of genes was quantified using qRT-PCR. Bars represents $\mathrm{N}$-sufficient (black) and $\mathrm{N}$ deficient (white) treatment. The statistical significance in transcript abundance induced by $\mathrm{N}$ deficiency is indicated by asterisks (Student's t-test, ${ }^{* * *}: \mathrm{p}<0.001$ ), error bars represent $\pm \mathrm{SD}$.

Figure 6 . Effect of nitrogen $(\mathrm{N})$ deficiency on growth of Arabidopsis thaliana pip mutants. Plants were grown in the presence of either $60 \mathrm{mM}$ (sufficient) or $30 \mathrm{mM}$ (deficient) $\mathrm{NH}_{4} \mathrm{NO}_{3}$. Leaves fresh weight was determined after 5 weeks of cultivation. Bars represents $\mathrm{N}$-sufficient (black) and $\mathrm{N}$ deficient (white) treatment. The data present the mean of 8 plants per treatment for 3 independent growth experiments. Letters above the histogram columns indicate significant differences in mean values, as predicted by a two way ANOVA (p-value $<0.05$ ), error bars represent \pm SD.

Figure 7 . The response of Arabidopsis WT and pipmutants to nitrogen deficiency. A- Nitrogen (N) and carbon (C) content of the leaves. B- Leaf phenylpropanoid and anthocyanin contents. Bars represents Nsufficient (black) and $\mathrm{N}$ deficient (white) treatment. The data present the mean of 8 plants per treatment for 3 independent growth experiments. Letters above the histogram columns indicate significant differences in mean values, as predicted by a two way ANOVA ( $\mathrm{p}$-value $<0.05$ ), error bars represent $\pm \mathrm{SD}$.

\section{Supplementary Data}

Supplementary Table S1. Primers used for identification of mutation homozygotes among the progeny of Arabidopsis T-DNA insertionpip mutant lines.

Supplementary Table S2 . Primers used for cloning of potato aquaporins.

Supplementary Fig. S1 . Identification of mutation homozygotes among the progeny of Arabidopsis TDNA insertion pip mutant lines.

Supplementary Fig. S2 . Effect of nitrogen deficiency on growth of potato genotypes. Supplementary Fig. S3 . Relative quantification of Western blot signal for determination of PM enrichment.

Supplementary Fig S4 . LC-MS based plasma membrane protein profiling of the two cultivars under N deficiency and control conditions analyzed by principal component analysis. Supplementary Fig. S5 . Number of transmembrane helices (TMH) predicted for the identified proteins.

Supplementary Fig. S6 . Localization of GFP:StPIPs in yeast cells.

Supplementary Fig. S7 . The ammonium transport ability of PIP1;1 and PIP1;3 studied in yeast by a growth complementation assay (without ZmPIP2;5 co-expression).

Supplementary Fig. S8 . Correlation between the abundance of PM ATPase and NRT2.1.

\section{Hosted file}

Figures Jozefowicz et al.docx available at https://authorea.com/users/329517/articles/456480plasma-membrane-intrinsic-proteins-pip1-1-and-pip1-3-contribute-to-the-tolerance-tonitrogen-deficiency-in-potato 